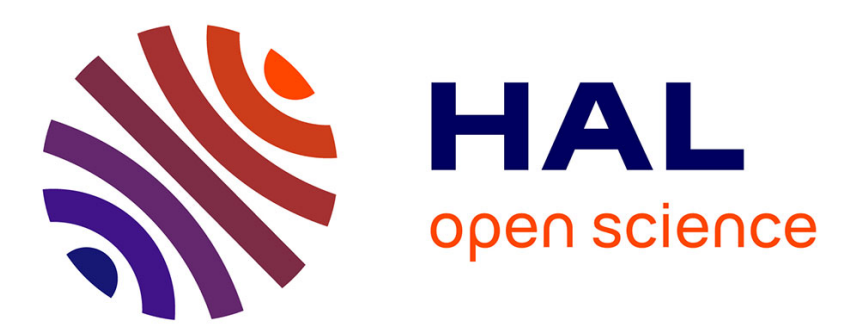

\title{
Dynamic fracture initiation in brittle materials under combined mode I/II loading
}

\author{
M. Nakano, K. Kishida, Y. Yamauchi, Y. Sogabe
}

\section{To cite this version:}

M. Nakano, K. Kishida, Y. Yamauchi, Y. Sogabe. Dynamic fracture initiation in brittle materials under combined mode I/II loading. Journal de Physique IV Proceedings, 1994, 04 (C8), pp.C8-695C8-700. 10.1051/jp4:19948106 . jpa-00253347

\section{HAL Id: jpa-00253347 https://hal.science/jpa-00253347}

Submitted on 1 Jan 1994

HAL is a multi-disciplinary open access archive for the deposit and dissemination of scientific research documents, whether they are published or not. The documents may come from teaching and research institutions in France or abroad, or from public or private research centers.
L'archive ouverte pluridisciplinaire $\mathbf{H A L}$, est destinée au dépôt et à la diffusion de documents scientifiques de niveau recherche, publiés ou non, émanant des établissements d'enseignement et de recherche français ou étrangers, des laboratoires publics ou privés. 


\title{
Dynamic fracture initiation in brittle materials under combined mode $\mathbf{I} / \mathrm{II}$ loading
}

\author{
M. Nakano, K. Kishida, Y. Yamauchi and Y. Sogabe*
}

Department of Precision Engineering, Faculty of Engineering, Osaka University, 2-I Yamada-Oka; Suita, Osaka 565, Japan

* Department of Mechanical Engineering, Faculty of Engineering, Ehime University, 3 Bunkyo-cho, Matsuyama, Ehime 790, Japan

\begin{abstract}
Resumé: On a développé un nouveau procédé en vue de mesurer la résistance d'initiation à la rupture dynamique pour des matériaux fragiles sous sollicitations de rupture combinée du mode $I$ et III. Les disques brésilien à fissure centrale ont été fracturés sous sollicitations d'impact oblique en compression diamétrale. Les fracteurs d'intensité de contrainte dynamiques du mode $I$ et Il sont évalués à partir des intégrales de superposition sur les fonctions de réponse à échelon pour le disque fissuré. Les résultats expérimentaux sont présentés en vue d'examiner l'influence de la vitesse de chargement sur la ténacité d'un mode de rupture combinée pour une céramique et des verres.
\end{abstract}

\begin{abstract}
A new test method has been developed to measure the resistance of dynamic fracture initiation in brittle materials under combined mode $I / I$ loadings. The Brazilian disks with center-cracks have been fractured under oblique impact loadings in diametral-compression. The dynamic stress intensity factors of mode $I$ and II are evaluated from the superposition integrals of the step response functions for the cracked disk. The experimental results are presented to elucidate the influence of loading rate on the combined mode fracture toughness for ceramics and glasses.
\end{abstract}

\section{INTRODUC'TION}

In an ordinary case that an impact load acts on a structure, stress waves obliquely impinge to various cracklike flaws in the components. The stress waves produce combined mode stress states around the crack-tips. Thus the dynamic fracture initiation criterion under combined mode loadings has to elucidate for assessments of structural integrity in relation to the impact fracture. Accurate evaluations of the dynamic fracture toughness can be achieved by development of fully dynamic test procedures including precise analyses of dynamic stress intensity factors for all modes.

In order to assess pure mode $I$, pure mode $I$ and combined mode fracture toughness of brittle materials, center-cracked Brazilian disk specimens have been used under quasi-static loading [1,2]. Combined mode stress states in the disk specimens can be controlled by selecting the inclination angle $\theta$ of the center-precrack relative to the line of loading. Pure mode $I$ is obtained at the angle $\theta_{I}=0^{\circ}$ by loading in compression along a diameter through the precrack. Pure mode II is achieved at $\theta_{I I} \simeq 23^{\circ}$ for $a / R \simeq 0.5$, where $a$ is the half length of the center-crack and $R$ the radius of the disk $[2,3]$. This quasi-static fracture test technique in diametral-compression is particularly attractive because of the simple loading and specimen geometry. Thus we have developed a new test method for combined mode impact fracture using the center-cracked disk specimen. The impact fracture tests can be performed under arbitrary combinations of mode $I$ and II by varying the inclination 


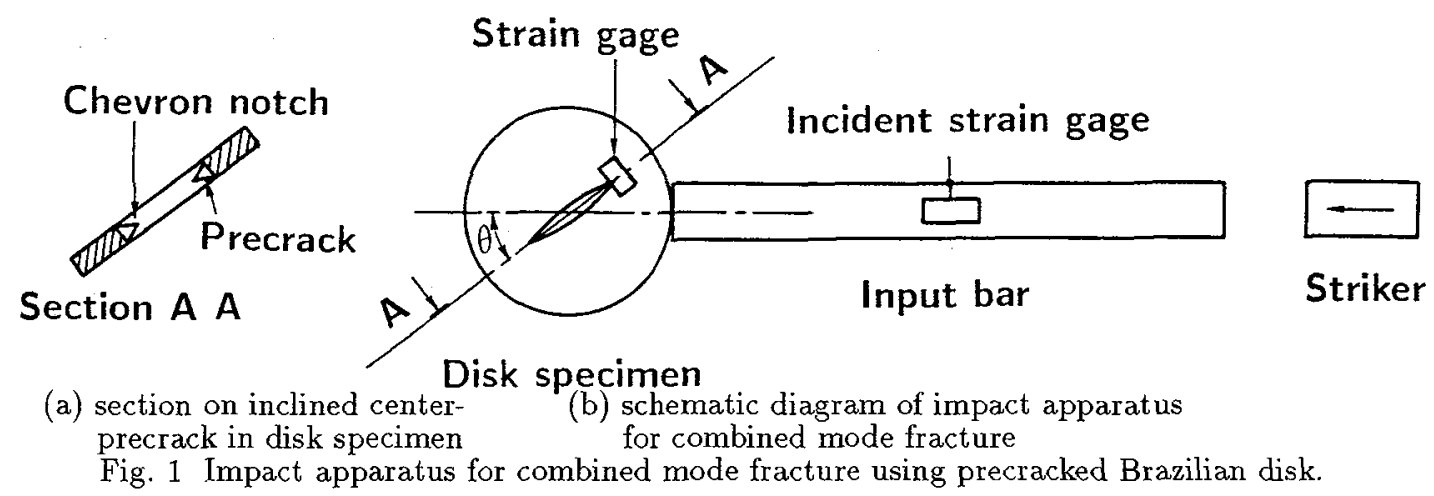

angle $\theta$ of the center-crack.

The dynamic fracture toughness values of mode $I$ and $I$ are determined from critical dynamic stress intensity factors at fracture initiation. The dynamic stress intensity factors of mode $I$ and $I I$ are calculated by superposing the step-response functions with respect to the impact load history measured in the fracture test $[4,5]$. The step-response functions have been obtained from the finite element analyses [6] for the precracked disk specimen. The onset of fracture initiation is detected using the strain gage near the crack-tip. In the present study, static and dynamic fracture tests are performed for ceramics and glasses under pure mode $I$, pure mode $I$ and combined mode loading. The dynamic results are compared with the quasi-static data obtained in diametral-compression fracture tests for the brittle materials.

\section{APPARATUS AND EXPERIMENTAL METHOD}

The impact apparatus for combined mode fracture principally consists of the disk specimen with center-precrack, an input bar and a striker as shown in Fig. 1. The experimental materials were a fine-grained polycrystalline alumina $\mathrm{Al}_{2} \mathrm{O}_{3}$ with $2.5 \mathrm{~mm}$ thickness $B$, a sealing glass $(B=3 \mathrm{~mm})$ used for electronic ceramic packaging and a commercial soda-lime glass $(B=3 \mathrm{~mm})$ for window. The geometry of these disk specimens was $36 \mathrm{~mm}$ in diameter $2 R$. As shown on a section drawing in the figure (a), symmetric chevron notches were machined at the center of the disk using thin diamondgrit blades $[1,7]$. After machining, precracks were grown within the chevron notches by pure mode $I$ static loading to $90 \%$ of the static fracture load. The resulting length $2 a$ of the center-precrack was about $17 \mathrm{~mm}$ (the normalized crack length $a / R \simeq 0.5$ ). The input bar and the striker were made of a high-strength steel bar with 8 mm diameter.

The one-point impact tests in diametral-compression were conducted using the precracked Brazilian disks for the inclination angle $\theta$ between $\theta_{I}=0^{\circ}$ and $\theta_{I I} \simeq 23^{\circ}$. A compressive wave was generated by the longitudinal impact of the striker, and propagated along the input bar in Fig. 1(b). Part of the compressive incident pulse was transmitted through the disk specimen and caused its combined mode fracture, while part of which was reflected back to the input bar. According to the one-dimensional theory of elastic wave propagation, the impact load $P(t)$ was calculated from the incident and reflected pulses measured with the strain gage mounted on the input bar. The onset of fracture initiation was detected using the other strain gage near the right crack-tip as shown in the figure.

\section{COMPUTATION OF DYNAMIC STRESS INTENSITY FACTOR}

Dynamic fracture toughness values of mode $I$ and II can be defined as the critical dynamic stress intensity factors at fracture initiation for the right crack-tip, because we confirmed that the initial crack extension surely occurs at the right crack-tip of the disk specimen in Fig. 1. This dynamic stress intensity factor $K_{i}^{\theta}(t)$ of mode $i(=I, I)$ for the inclination angle $\theta$ is computed from the following convolution integrals:

$$
K_{i}^{\theta}(t)=A_{i} \int_{0}^{t} h_{i}^{\theta}(t-\eta) \dot{P}(\eta) d \eta \quad ; \quad i=I, I
$$

where $h_{i}{ }^{\theta}(t)$ is the step-response function for the right tip and $\dot{P}(t)$ the time derivative of the impact load history measured in the fracture test. $A_{i}$ is a coefficient for mode $i$, which is calculated from the 


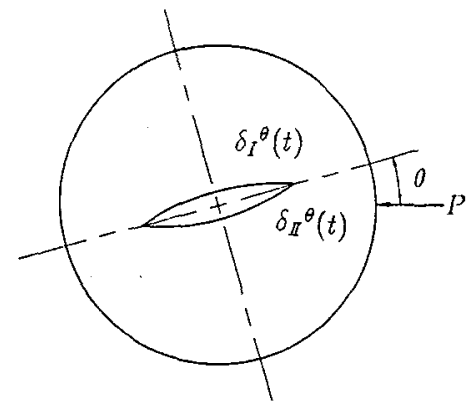

(a) combined mode step impact

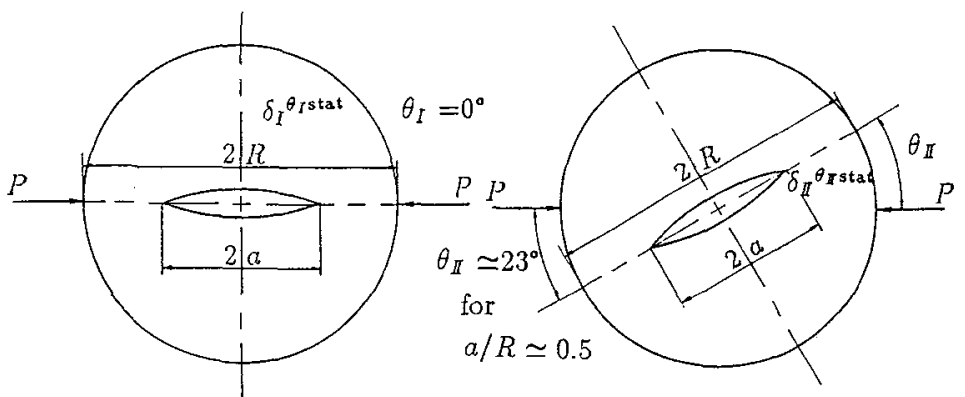

(b) pure mode $r$ static

(c) pure mode II static

Fig. 2 Boundary conditions in numerical analyses for step response functions $h_{I}^{\theta}(t)$ and $h_{I I}^{\theta}(t)$.

nondimensional coefficient $N_{i}$ in the static formula of the stress intensity factor $K_{i}^{\theta_{i} \text { stat }}$ for the specific angle $\theta_{i}$ under pure mode $i$ loading:

$$
A_{i} \equiv \frac{K_{i}^{\theta_{j} \text { stat }}}{P}=\left[\frac{\sqrt{\pi a}}{\pi R B} N_{i}\left(\theta_{i}\right)\right]_{\text {pure mode } i} \quad ; \quad i=I, \mathbb{I}
$$

where $N_{I}$ for $\theta_{I}=0^{\circ}$ has been obtained by Ishida et al. [8] and $N_{I I}$ for $\theta_{I I}$ by Awaji et al.[2]. Atkinson et al. [3] have given solutions of the nondimensional coefficient $N_{I}$ and $N_{I I}$ in terms of series under combined mode static loading for the angle $\theta$.

Since the crack-opening and shear displacement near the crack-tip are proportional to the mode $I$ and II stress intensity factors respectively, the step-response function $h_{i}{ }^{\theta}(t)$ is obtained from the following relation:

$$
h_{i}^{\theta}(t) \equiv\left[\frac{K_{i}^{\theta^{\theta}}(t)}{K_{i}^{\theta_{i}{ }^{\text {stat }}}}\right]_{\text {step }} \simeq\left[\frac{\delta_{i}^{\theta}(t)}{\delta_{i}^{\theta_{i} \text { stat }}}\right]_{\text {step }} \quad ; \quad i=I, I I
$$

where $\delta_{I}{ }^{\theta}(t)$ and $\delta_{I}{ }^{\theta}(t)$ are the dynamic mode $I$ and $I$ displacements near the right tip under combined mode step impact for the inclination angle $\theta$ in Fig. 2(a). On the other hand, $\delta_{I} \theta_{I}$ stat and $\delta_{I I}^{\theta_{I} \text { stat }}$ are the static corresponding displacements under pure mode $I$ and $I$ loading for $\theta_{I}=0^{\circ}$ and $\theta_{\text {II }} \simeq 23^{\circ}$ in the figures (b) and (c). We can obtain these displacements from the dynamic and static finite element analyses, in which the step load $P$ is assumed to be applied at $t=0$ with Heavisidefunction time dependence. The finite element mesh for computing the step response functions is presented in Fig. 3. The isoparametric plane-strain elements with four nodes are employed. The time integration scheme is Newmark- $\beta$ method with $\beta=1 / 4$. Details of the numerical analyses have been described in our previous paper [6].

Typical time variations of the step response function $h_{i}{ }^{\theta}(t)$ are represented in Fig. 4 for the alumina ceramics at the angle $\theta=15^{\circ}$. Effect of inertia is evident in the figure. It was found that the peak of $h_{I}{ }^{\theta}(t)$ decreases with increasing the inclination angle $\theta$, while that of $h_{I}^{\theta}(t)$ increases.

\section{EXPERIMENTAL RESULTS AND DISCUSSIONS}

Figure 5 shows output records of the strain gages in the typical impact fracture test for the alumina ceramics at the inclination angle $\theta=15^{\circ}$. The compressive incident stress $\sigma_{\mathrm{i}}$ and the tensile reflected pulse $\sigma_{\mathrm{r}}$ are measured with the incident strain gage on the input bar. The lower output signal of the gage near the right crack-tip shows the sudden drop at the fracture initiation and then increases in the break of the strain gage due to crack growth.

Figure 6 represents the typical time variation of the impact load $P(t)$ calculated from the incident and reflected pulses according to the one-dimensional theory of elastic wave propagation. Figure 7 presents time variations of the dynamic stress intensity factors of mode $I$ and $I I$ for the typical test. The dynamic fracture toughness values of $K_{I f}$ and $K_{I f}$ are determined as the critical stress intensity factors at fracture initiation $t_{f}$ as shown in the figure. 


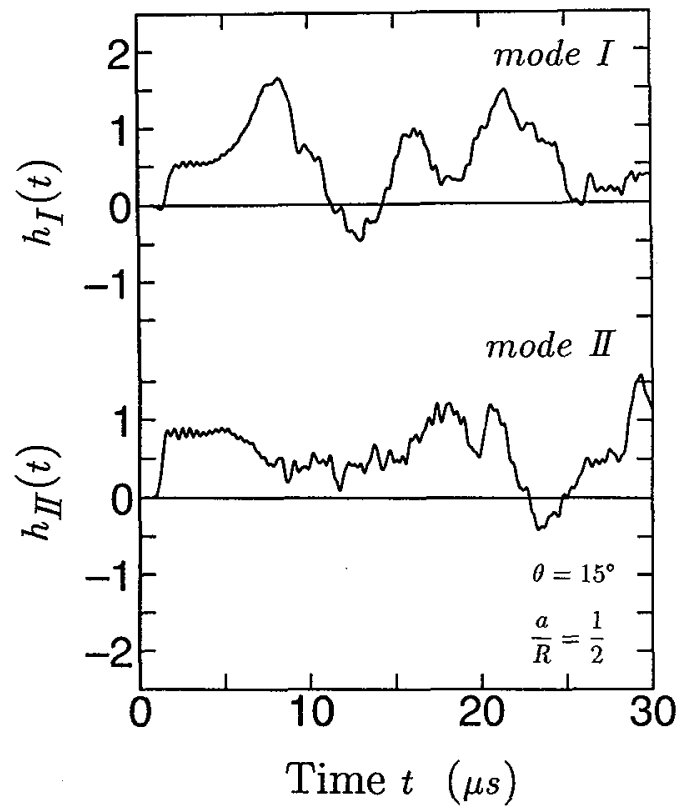

Fig. 4 Step response functions of cracked disk for alumina ceramics at inclination angle $\theta=15^{\circ}$.

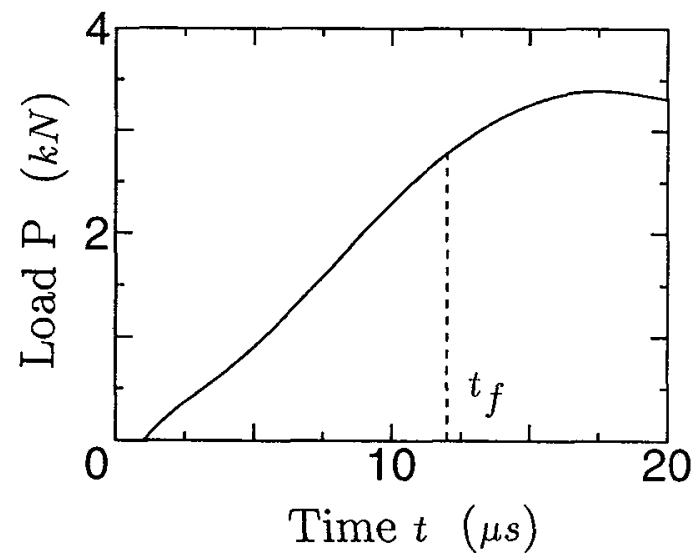

Fig. 6 Typical time variation of impact load $P(t)$ for alumina ceramics at $\theta=15^{\circ}$.

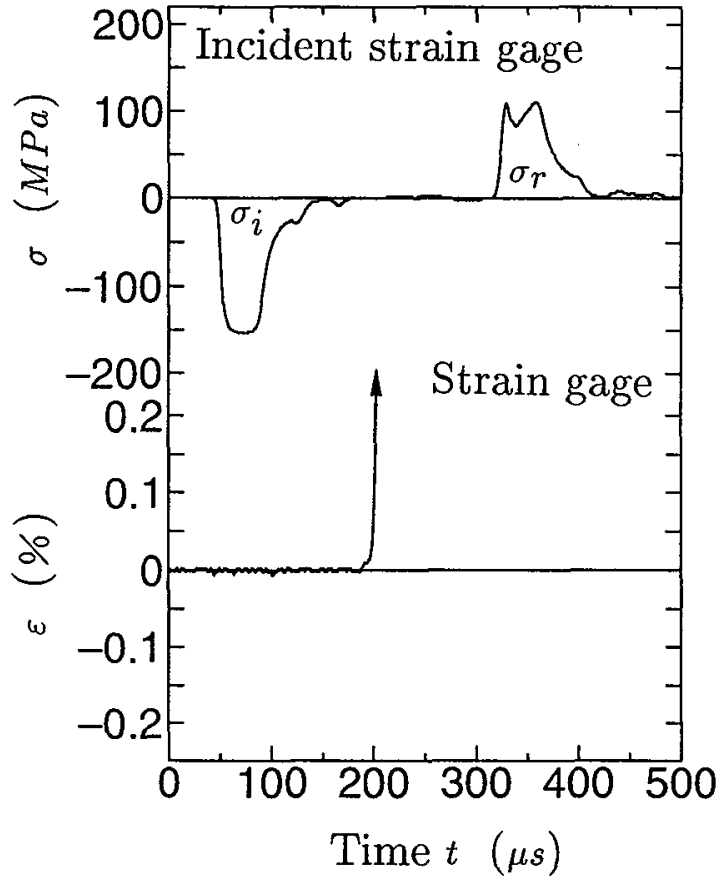

Fig. 5 Typical output records of strain gages in impact fracture test for alumina ceramics at $\theta=15^{\circ}$.

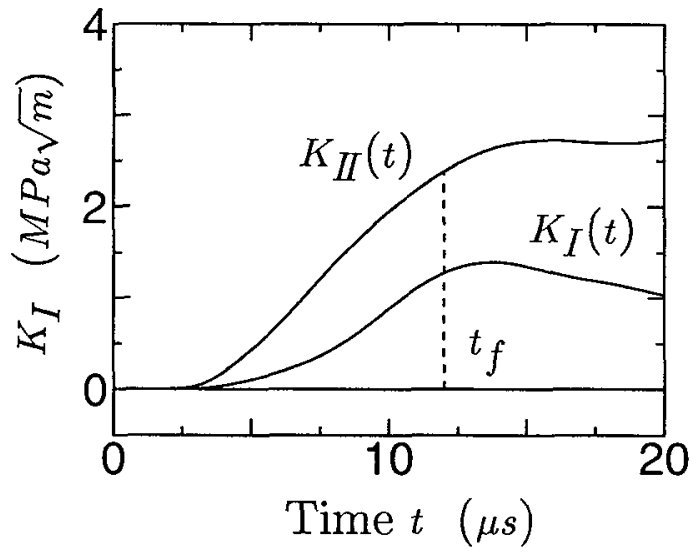

Fig. 7 Typical time variations of dynamic stress intensity factors of mode $I$ and II for alumina at $\theta=15^{\circ}$. 


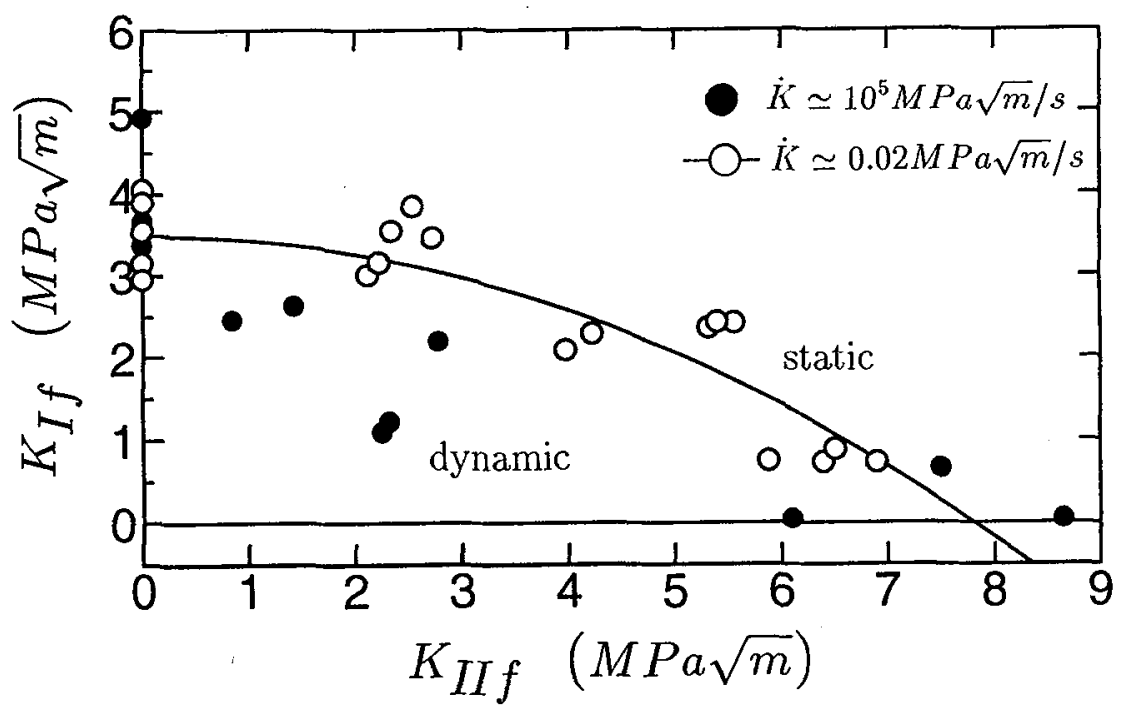

(a) alumina ceramics $\left(\mathrm{Al}_{2} \mathrm{O}_{3}\right)$

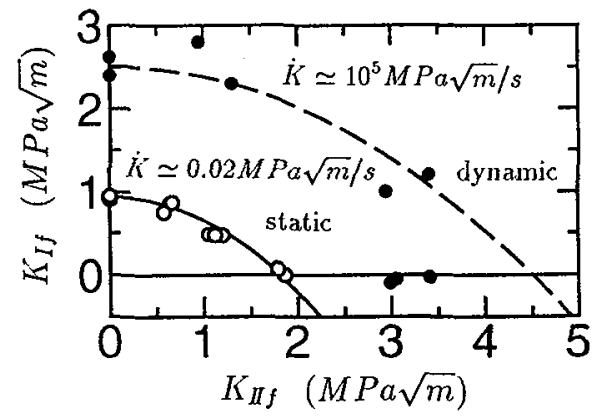

(b) sealing glass

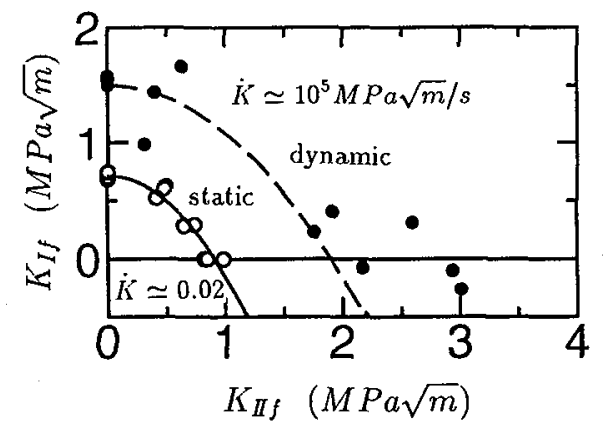

(c) soda-lime glass

Fig. 8 Dynamic and static data of fracture toughness for the brittle materials under combined mode loadings.

Figure 8 shows the dynamic data of combined mode fracture toughness assessed under impact loadings at very high loading rate $\dot{K} \simeq 10^{5} \mathrm{MPa} \sqrt{\mathrm{m}} / \mathrm{s}$ for the alumina ceramics and the glasses. These dynamic results are compared with the static data obtained in the diametral-compression tests at $\dot{K} \simeq 0.02 \mathrm{MPa} \sqrt{\mathrm{m}} / \mathrm{s}$ using a conventional universal testing machine.

Figure 8 represents the relationship between the experimental results and the fracture initiation criterion for combined mode $I$ and $I I$ as the following empirical equation:

$$
\frac{K_{I f}}{\alpha K_{I c}}+\left(\frac{K_{I f f}}{\alpha K_{I c}}\right)^{2}=1 \quad \text { for static }(\alpha=1) \text { and dynamic }\left(\alpha=\frac{K_{I d}}{K_{I c}}\right)
$$

where the static empirical equation of $\alpha=1$ (solid line curves in Fig. 8) has been used by some investigators [see, for instance 1,7]. $K_{I c}$ and $K_{I c}$ are the static fracture toughness values of pure mode $I$ and $\bar{I}$ respectively. $K_{I d}$ is the dynamic value of pure mode $I$ fracture toughness and the ratio $K_{I d} / K_{I c}$ is $\alpha$ in the dynamic empirical equation (dashed line curves in Fig. 8 ).

For the alumina ceramics, the pure mode $I$ fracture toughness presents no effect of the change in loading rate $\left(K_{I d} / K_{I c} \simeq 1.0\right)$. Since the difficulty in detecting the onset of dynamic fracture initiation increases with the inclination angle $\theta$, the dynamic data are scattered under combined mode loadings. 
These scattered data in Fig. $8(\mathrm{a})$ indicate that the influence of loading rate on fracture toughness is not clearly seen in the alumina ceramics.

On the other hand, the dynamic fracture toughness values for the sealing glass and the sodalime glass become higher than static values under any combined mode loading as shown in Fig. 8(b) and (c). The results of static fracture toughness for the soda-lime glass in the figure (c) are similar to the data reported by Singh et al.[1] and Shetty et al.[7]. Considering these scatter in Fig. 8, the dynamic curves of the simple criterion of Eq.(4) can be applicable to the data of the combined mode fracture toughness at high loading rates.

The mode II fracture toughness value was larger than that of mode $I$ for all materials in Fig. 8. It seems that one reason of the difference between mode $I$ and $I$ may be the effect of the second order nonsingular terms in the expressions for the crack-tip stresses. Previously, Shetty et al.[7] have pointed out the importance of this effect on the static data, which have obtained in the uniaxial tension and the diametral-compression tests. However, the assessments of the second order nonsingular terms must be harder under impact loadings. Comparing the present study with fracture toughness data for asymmetric impact bend tests in the brittle materials, it is useful to investigate this effect on dynamic fracture toughness under combined mode loading.

\section{SUMMARY AND CONCLUSIONS}

A fully dynamic procedure was developed for the measurement of combined mode fracture toughness at high loading rates. The Brazilian disks with center-cracks were fractured under oblique impact loading in diametral-compression. The dynamic stress intensity factors of mode $I$ and II were evaluated from the superposition integrals of the step response functions for the cracked disk. The step response functions were obtained from the dynamic and static solutions of finite element analyses[6]. The onset of fracture initiation was detected using the strain gage near the crack-tip[5]. The combined mode data of dynamic fracture toughness for the ceramics and glasses were obtained from the critical values of dynamic stress intensity factor at fracture initiation under very high loading rate $\dot{K} \simeq 10^{5} \mathrm{MPa} \sqrt{\mathrm{m}} / \mathrm{s}$ by the present method. For the alumina ceramic, the influence of loading rate on the combined mode fracture toughness is not clearly seen. On the other hand, the fracture toughness for the glasses increases with loading rate under any combination of mode $I$ and $I I$.

Acknowledgments - The authors would like to express their appreciation to the former graduate students Mr. Y. Watanabe, Mr. Y. Sugimoto and Mr. H. Nakano for their technical assistance in the performance of the experiments. This research was supported by the Grant-in-Aid for General Scientific Research from the Ministry of Education, Science and Culture. We wish to thank Nippon Electric Co.,Ltd., Sumitomo Metal Ceramics Industries, Ltd., and Nippon Electric Glass Co.,Ltd. for the help in preparing the test specimens. The finite element analyses were carried out using NEC-ACOS computer at Computation Center Osaka University.

\section{REFERENCES}

[1] Singh D. and Shetty D.K., J. Am. Ceram. Soc. 73 (1990) 3597-3606.

[2] Awaji H. and Sato S., ASME J. Eng. Mat. Tech. 100 (1978) 175-182.

[3] Atkinson C., Smelser R.E. and Sanchez J., Int. J. Fract. 18 (1982) 279-291.

[4] Nakano M. and Kishida K., Int. J. Pres. Ves. Piping 44 (1990) 3-15

[5] Nakano M., Kishida K. and Watanabe Y., "Mixed-mode impact fracture tests using centernotched disk specimens", Int. Symp. Impact Eng. 2, Sendai 2-4 November 1992, pp.581-586.

[6] Nakano M. and Kishida K., Eng. Fract. Mech. 36(1990) 515-522.

[7] Shetty D.K., Rosenfield A.R. and Duckworth W.H., Eng. Fract. Mech. 26(1987) 825-840.

[8] Isida M., Eng. Fract. Mech. 7(1975) 505-514. 